\title{
MALAS DOÑAS
}

\author{
Manuel Palazón Blasco \\ F. P. A. Miguel Hernández, Sagunto
}

\section{Prólogo}

Las malas doñas del mito que han relatado los hombres de todos los tiempos, y aquí y allá, tienen la gana furiosa y la vagina dentada y colmilluda ( $\mathrm{y}$ mellada), y son siempre (o las hacen) de fuera, de otro lugar (del Otro lugar). Delante de Lilith, la de Entre Ríos, delante de la africana Lamia o de las empusas griegas, delante de nuestras serranas, tiemblan de miedo y de amor él y Él.

Reúno aquí a diosas, diablesas y mujeres, todas de cuento, que fueron desnaturadas, extrañadas, echadas de lo suyo, enviadas noramala, borradas de la historia, y tuvieron que hacerse madriguera (que no patria, las patrias son artificios del macho) en las soledades. No quisieron someterse, ni sufricron que las señoreasen, y huyendo de los tiranos sólo hallaron descanso disimulándose entre la Palabra escrita, (masculina), buscando los márgenes del mundo (desiertos, sierras, peladeros) y de la realidad (donde más pueden, todavía, es en los sueños). A algunas les mataron (les matan a diario) a los hijos, y se vengan (o encuentran consuelo) robando recién nacidos. Todas reciben cicrta satisfacción asaltando a los hombres desprevenidos y arrancándoles, después de gozarlos, la cabeza.

\section{Lilith}

\section{1. Isaías, XXXIV}

Lo que Yahvéh no alcanza a avasallar lo arrasa. Dando mandobles, escupiendo fuego, soltando diluvios, enredando las lenguas de los hombres. Lilith, la condenada, malvive en una de esas soledades malditas. Habló Isaías, vocero de Yahvéh, y su saliva emponzoñó el país de Edom. Se enrollaron los cielos como un libro antiguo. Desde entonces los pastores desvían sus rebaños, no plantan tienda los árabes, las caravanas pasan de largo. Humea aún la tierra quemada. El alquitrán 


\section{MALAS DOÑAS}

y la sangre y la grasa de las reses y de los soldados embarran sus ríos. Los espinos, las ortigas y los cardos han invadido sus jardines maravillosos. Buitres, cuervos, pelícanos y bandurrias se han repartido el aire. En aquel derrumbadero son vecinos de Lilith la hiena, la víbora, el chacal, el cabrón, el erizo, el avestruz. Un mochuelo la acompaña. A Lilith, la lechuzona. Lilith sólo asoma en la Biblia citada por Isaías, el agorero:

también allí reposará Lilith

y en él encontrará descanso.

(Isaias, XXXIV, 14)

Los autores del Libro procuraron evitar los nombres de las diosas que su severo y celoso señor venía a echar de sus templos, de sus ciudades sagradas. Éste se les coló. Luego, exégetas y traductores corrigieron la indiscreción, y donde decía "Lilith" dijeron "chillona lechuza":

Tenderá Yahvéh sobre ella la plomada del caos

y el nivel del vacío.

(Isaías, XXXIV, 11)

Yahvéh juraba (y se cumpliría) devolver a Edom y a Babilonia (como ya había hecho con Sodoma, Gomorra y las demás villas de aquella viciosa comarca) a la nada original, al tohu y bohu ("el desierto y el vacío" del Génesis, I, 2) del principio de los tiempos, de cuando todavía su aliento no había fecundado las turbias aguas primordiales, de cuando su Palabra no había aún nombrado (creándola mágicamente) la luz. Pues en esas terribles parameras, en esos paisajes que repiten tanto el mundo anterior a El (Él, claro, siempre) como el de su final catastrófico (Apocalipsis, XVIII, 1-3) se ha hecho huronera, huida, nuestra Lilith.

\section{2. Diosa entrerriana}

Lilith fue, bajo otros nombres, diosa muy venerada en la Mesopotamia, con señorío en sus dos orillas, la izquierda de los desiertos infinitos y la derecha de las orgullosas cordilleras. Allí le rendía pleitesía toda la salvajina. A esta Lilith se encomendaban las comadronas, y como tal la consideraron, un poco, Madre o Madrina universal. Vecina de una serpiente y de una pájara, la virgen Lilith vivió en el hueco de un sauce sagrado que Inanna (la Astarte que acorralarán los hebreos) había plantado en el Jardín de las Delicias hasta que Gilgamesh, el héroe de más solera de los cuentos, desalojó a los monstruos, pues secaban el árbol fantástico. Lilith huyó al desierto.

Lilith (si es ella) viene retratada en dos tablillas sumerias. La pintan alada, con garras de ave, la cabeza tocada con una tiara de cuernos retorcidos, con un haz de bichas en la mano, acompañada de búhos, apoyada, en una, sobre dos leones, y en la otra sobre dos íbices. Vino Él (El, Yahvéh) mucho más tarde, y era muy suyo y gran acaparador, y mandó que sus escribas borrasen de su Libro y de la memoria los nombres de todos los diosecillos oriundos de su Tierra Santa. A Isaías, sin embargo, se le pasó Lilith. El profeta puso a Lilith entre los restos de la asolada Edom, con otras alimañas. La Biblia inglesa del rey don Yago esconde a Lilith, traduciéndola por "lechuza chillona". Buscaba ocultarla, pero en cierto modo revela su aspecto primitivo, ha recordado sus garras, sus alas.

En el Midrash se cuenta que hubo «una primera Eva», pero que Adán la encontró repugnante y Dios «la devolvió al polvo». El Talmud Babilónico, terminado hacia el año 650, ordena las notas que los estudiosos habían ido haciendo del Mishna a lo largo de varios siglos. El Talmud cita a Lilith. Dice que Adán, durante su penitencia, separado de Eva, engendró en sueños (sin querer) «ogros, demonios y lilin». Lilith, dice, se adueña de los hombres que duermen solos en sus casas. Lilith es peluda, dice, y tiene alas.

El Zohar ("el Libro del Esplendor") de Moisés de León (1250-1305) y la Cábala, que buscaban desvelar los misterios que la Letra ocultaba, recogieron noticias, tradiciones y consejas muy 


\section{MANUEL PALAZÓN BLASCO}

diversas sobre Lilith. Contaron que, mientras que a Adán lo hizo Elohim con barro de la tierra más sagrada, para Lilith empleó lodo. Que Adán y Lilith nacieron siameses, y cuando Dios los separó y Adán, hambrón, intentó montar a Lilith, ésta, pronunciando el nombre secreto de Dios, pudo escapar al desierto, donde se entregaba a los sátiros, de quienes tenía cada día cien hijos, o lilin. Que Dios le envió tres ángeles para obligarla a regresar con Adán, pero ella no quiso. Desde entonces los esclavos de Dios le matan a diario a sus hijos, y ella, la demonia, roba o estropea los niños de las mujeres más despistadas y se cuela en los sueños de los hombres, concibiendo así de ellos generaciones y generaciones de diablos. Los que gustan garabatear en los márgenes de la Biblia han visto a Lilith en el Leviatán, en la serpiente del Edén, en la prójima de los proverbios, en la que deja a Job sin herederos, en la reina de Saba, en una de las madres del famoso juicio salomónico...

\section{Lamia}

Tanto por su pinta como por sus costumbres muchos hacen a Lamia hija o hermana de Lilith, o aseguran que se trata de la misma mala mujer, que, aburrida de Adán, vino a parar a Libia. Clareaba cuando Baal eyaculó en Canaán: el levante llevó su blanco rocío hasta Libia y la empapó. Del barrillo que trajo aquella lluvia mañanera nació Lamia para reinar en el país. Zeus, empalmado, iba pisándole las faldas a alguna ninfa, y al pasar por Libia se topó con su reina. El griego y la africana cruzaron amores. En su corte cirenaica Lamia criaba con mil mimos a la prole de Zeus. Hera se enteró. Los celos le revolvieron los humores. Entró en el serrallo del alcázar libio una tarde y pasó a cuchillo a todas las criaturas delante de la reina madre. Sólo se salvó Escila, la pobre. «Cada vez que cierres los ojos, Lamia, mala puta, soñarás minuciosamente el horror de esta degollina. Se te habrán ido las ganas, supongo, de mi marido».

Lamia huyó de Cirene dejando abiertas las puertas del palacio y de la ciudad y a la pequeña Escila temblando en medio del recibidor, porque no quería que nada ni nadie estorbasen su venganza. Se hizo madriguera en una caverna. Allí dentro apaciguaba el hambre y la rabia devorando niños que robaba en los alrededores. Pero el espanto y la pena la seguían en sus pesadillas, y dio en no dormir. La vigilia la cansaba, la enloquecía. A Zeus le dio lástima su antigua novia. Hurtándose al espionaje de su esposa fuc a verla un día:

- ¿Cómo estás?

-De atar. Rota. Desvelada.

-Te haré un favor...

- ¿Otro aún? ¡Malo...! De tus favores nacen mis desgracias.

-Te voy a traer un dormir dulce. Llamaré a San Dionisio, te plantará unas cepas, te enseñará a criar buen vino, te pondrá la bodega en el fondo de la cueva. Con ese vino y con este otro truco podrás soñar tranquila.

$\mathrm{Y}$ así fue que por gracia de Zeus Lamia podía ponerse y quitarse los ojos como mejor le cuadraba. Ciega, con las cuencas vacías y los ojos en una taza de aceite, se atrevía a buscar cl sueño, y lo terminaba encontrando con la ayuda del caldo de San Dionisio. No siempre llevó la troglodita una vida solitaria. De a poco se fue haciendo el ánimo. Primero se juntó con unas bandoleras de aquellos montes, ahijadas de Hécate. Como eran muditas tampoco pedían mucha conversación, ni estaba Lamia para darla. Se agazapaban en la orilla de los caminos y con una canción silbada paraban al viajero; entonces se echaban sobre él y se lo comían allí mismo. Para Lamia era un cambio bienvenido: la carne del caminante estaba más prieta, menos tierna, pero eso iba en pagas de los afanes compartidos con las otras pandilleras, la furia del ataque, las carcajadas del festín. Dicen que asustaba su aspecto: con una máscara tan fea como su desgracia se ocultaba el rostro, y de la cintura para abajo parecía serpiente (así imaginaron también, acuérdate, a Lilith). 


\section{MALAS DOÑAS}

Luego se volvió fina, sibarita. De tarde en tarde se iba con las Empusas. Éstas asaltaban a los hombres dormidos, despreciaban su carne, los desangraban a colmilladas.

El Diccionario de Autoridades trae las distintas versiones de la lamia legendaria, y añade dos significados curiosos:

I.AMIA. Se llama también la mujer pública o ramera...

LAMIA. Pescado cetáceo de desmesurada grandeza... Es muy cruel y tragador de carne...

Bajo esta acepción cita como autoridad a Plinio (IX, 46), en la traducción de Jerónimo de Huerta: «Ha sucedido hallarse en el vientre de una Lamia un hombre entero con su loriga y arnés: y por esta causa entienden algunos Autores haber sido Lamia la que tragó al Profeta Jonás». Lamia, como antes lo fuera Lilith, es el Leviatán, el pez de los comienzos del mundo, el pescado que servirán en el banquete último.

Covarrubias también habla de las lamias, describiéndolas como «fantasmas de malos espíritus, que en forma de mujeres muy hermosas atraían a sí los niños y los mancebos con halagos y últimamente los mataban y se los comían...». Las pone en África como «cosa vulgarmente recibida» y concluye: «Lo más cierto es ser cierta especie de monas». Sin embargo, lo más llamativo es la cita que hace de Isaías (XXXIV, 14): «Ibi cubavit lamia, et invenit requiem» («Allí reposa la lamia, y encuentra descanso...») ¡Pues traduce Lilith por Lamia!

\section{Empusas}

Las empusas son las damas de Hécate. A la patrona de las brujas y señora del Infierno de tributo le traen almas de varones descuidados. Ellas se quedan con la chicha. La empusa gasta ancas de borrica y calza zuecos de bronce para disimular las pezuñas. Busca aposta los caminos empedrados, alborotando con su torpe trote y sus rebuznos. Mientras el hombre duerme no hay modo de guardarse, está desamparado. Entonces se cuela en su sueño cualquier empusa, a medio vestir y guapísima, y muere despacito, con mucho gusto, desangrado.

\section{Serranas}

\section{1. Villanescas}

"Serranas" y "serranillas" se desparecen de los cultos coloquios entre guardacabras sutiles, cursis, que cultivaron Teócrito, Virgilio, Garcilaso o Camões, y también de las pastorelas provenzales, gallegoportuguesas o francesas. Menéndez Pelayo o Alfredo Jeanroy las creyeron hijas bastardas de estas últimas (Menéndez Pidal, 1957: 174). Se ha dicho que el Arcipreste de Hita quiso hacer, con sus coplas, una grosera caricatura de esta poesía rústica. Es verdad que en unas y otras se tropieza un gentilhombre con una zagala, y que Amor los ronda siempre, aquí delicado, allá grosero. Sin embargo, los amenos prados, las deliciosas dehesas o las frescas fontanas, acomodados por una eterna primavera, son paisajes muy distintos de los inhóspitos cerros invernales por donde corren o brincan las montesinas. Nada tienen en común, tampoco, los corteses caballeros de unas con los bordes señoritos de las otras, y menos todavía las exquisitas borregucras de aquéllas (a menudo damas disfrazadas o escondidas) con las peligrosas brutas de éstas.

¿Tienen, entonces, madre las "serranas"? Valgan estas cuatro canciones ${ }^{1}$ populares como muestra de algunas más que, aunque recogidas tarde, entre los siglos XV y XVII, nacerían mucho antes, y pudieron, según defendió Menéndez Pidal (1957: 180), ser «el tema inicial o el germen de la serranilla literaria»:

1.- Están sacadas de la edición de Francisco Torrecilla del Olmo (1997). Él, a su vez, las copia del libro de Margit Frenk, Corpus de la antigua lírica popular hispánica (siglos XV a XVII) (1987). 


\section{MANUEL PALAZÓN BLASCO}

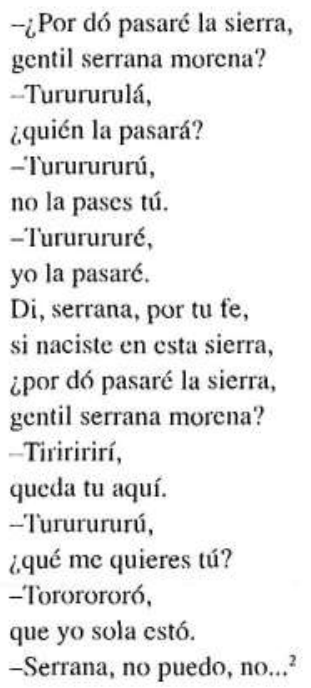

El caminante desorientado pide a esta serrana tempranera que sea su rumbeadora. Ella quierc, en vez de guiarlo, darle dulce habitación, y él la aparta, espantado como delante de una demonia: «¿Qué me quicres tú?» Están con ello, ya presentes, los elementos esenciales del género:

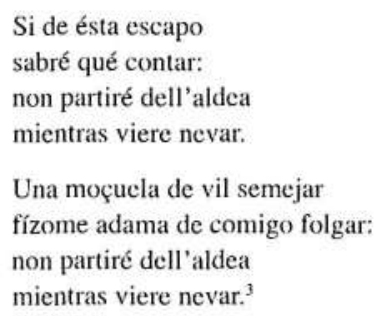

De nuevo el andarín (en ésta, un aldeano) recuerda el horror de la fea montañesa que le saltó encima haciendo gesto de holgarse con él. Le sirvió de escarmiento:

La más graciosa serrana,

que en el mundo no hay su par,

es Menga, la del boscar.

Con su çurrón y cayado

la vi ensomo la montaña, que salía de su cabaña

para guardar el ganado. ${ }^{4}$

Tocaya de Menga Llorente, la del arcipreste, y serrana de ley, ésta («la del boscar») tiene ya oficio de pastora:

A serra é alta,

fria e nevosa,

2.- Torrecilla del Olmo (1997: núm. 72, pp. 68-69).

3.- Torrecilla del Olmo (1997: núm. 78, p. 70).

4.- Torrecilla del Olmo (1997: núm. 79, p. 70). 


\title{
MALAS DOÑAS
}

\author{
vi venir serrana \\ gentil, graciosa. \\ $\mathrm{Vi}$ venir serrana \\ gentil, graciosa, \\ cheguey-me para ella \\ com gram cortesia. \\ Cheguey-me a ella \\ de gram cortesia, \\ disse-lhe: -Señora, \\ quereis companhia? \\ Disse-lhe: -Señora, \\ quereis companhia? \\ Dixo-me: -Escudeyro, \\ segui vossa via.s
}

Aquí se vuelven las tornas. Ya en la canción anterior el pocta se admiraba de la gracia de esa Menga. Este gallego con título, como el marqués de Santillana en algunas de sus canciones y el narrador de tantas pastorelas provenzales y francesas, busca engañar con pamplinas a la serrana, pero aquí es ella la que no se deja, doña Virtudes.

\section{2. Serranas que dijo conocer Juan Ruiz}

«Provar todas las cosas, el Apóstol lo manda: / fui a provar la sierra...» (950ab). El Arcipreste ya había utilizado la cita paulina cuando empezó la relación de su carrera de buen amador: «Provar omne las cosas non es por ende peor...» (76c) Con su uso torcido del «omnia probate» (I, Tesalonicenses, V, 21) Juan Ruiz se hace de la escuela de los goliardos (Gybbon-Monypenny, 1990: 305, nota a 950a). Salió, pues, a probar la sierra, a ensayarse en ella como caballero galán de cazurras. Su experimentación es (también) metapoética, puesto que hace (también) parodia de la pastorela (Gybbon-Monypenny, 1990: 19-20).

El Arcipreste de Hita (su yo real o fabuloso) se encontró en cuatro ocasiones con serranas. Escribió cada aventura primero en cuaderna vía, usurpando la estrofa del oficio de clérigos, puesto que él nos hablaba «en juglería» (1633b), y luego la glosó con una "cántica de serrana". Son, cualquiera que sea el metro que emplee, serranas o serranillas de mucha solera. $\mathrm{Y}$ también son serranas, digo, digo, las "cantigas" (1045d) que ofreció después a la Virgen del Vado.

En la primera iba para Sotos Albos (960b) y perdió «la mula, non fallava vianda» (950c). Marzo empezaba ceñudo en la cima del puerto de Malangosto, en el paso de Loyola. «Fazía nieve e granizava» (964a). Allí halló «una vaqueriza çerca de una mata; / pregunté le quién era, rrespondió me: 'La Chata; / yo só la Chata rrezia que a los omnes ata'» (952bed). Aquella "gaha [gafa, leprosa] rroín, heda [fea]» (961b) no lo dejaría pasar si no pagaba antes: "YYo guardo el portadgo e cl peaje cojo...'» (953a) Al de Hita le arrojó la cayada y lo asustó con su honda pedrera (963). Encogido, prometió que le mandaría «una garnacha» y «para el vestido» (966b) una «prancha con broncha, e con çorrón de coneja» (957d). La Chata se lo «echó (...) a su pescueço» para que no se cansara cruzando arroyos, subiendo y bajando las cuestas (958abc). En su «venta» (968b) hizo un buen fuego, y lo cebó con las cosas que sacaba a aquellos montes (968-969). Él empezó a desentumecerse, se calentaba, se «iva sonriendo». «Oteó» aquello la Chata y dijo: «'...Ya, compañón, agora / creo que vo entendiendo'» (970). Luego, «traviessa» (971a), quiso que luchasen un rato. Mandó que se desnudara. «Por la muñeca me priso, / ove de fazer quanto quiso; / creo que fiz buen barato» (97lefg).

5.- Torrecilla del Olmo (1997: núm. 81, pp. 70-71). 
Después de hacer turismo en Segovia y vaciar sus bolsillos, Juan Ruiz regresaba a su tierra, pero no por Lozoya, para evitar a la serrana, a la que debía cosas que no tenía, sino por el puerto de la Fuenfría. Otra vez se perdió. El extraviado va a la buena o a la mala de Dios. Éste se topó con otra vaquera valiente cerca de la aldea de Riofrío, en un pinar espeso. Con Gadea.

Primero, con su «cayada» (976c) lo «derribó» por el barranco (978a), y luego se lo llevó «a la cabaña», aprovechando que no estaba «Ferruzo» (980a), su marido. Si escotaba, dándole gusto, lo metería "por camino» y le daría «buena merienda» (980b). Como estaba «ayuno e arreçido» el Arcipreste dejó a Gadea a medias. Ella le «rogó (...) que fincase con ella esa tarde, / ca mala es de amatar el estopa, de que arde» (984ab), y él se excusó, tenía prisa. La serrana, decepcionada, lo acompañó hasta un cruce. Salían dos caminos, ambos usados. No le dijo cuál era el bueno. Juan Ruiz llegó con sol al pueblo de Ferreros, y de esta otra burla hizo otro cantar.

Era lunes y verano, pero el Arcipreste había salido antes del alba, con tal de pasar el puerto de mañana y llegar al pueblo antes de que oscureciese (993a; 996cd). Cerca de «la casa del Cornejo», lo encontró Menga Lloriente «descaminado» (998b). Él se fingió serrano, y le prometió matrimonio, y muchos regalos. Le dijo que corriese a convidar a sus parientes, y se largó, y la plantó (993-1005).

En la altura la escarcha se le coló en los huesos: por quitarse algo el frío bajó corriendo el puerto (1006-1007). En el fondo se llevó menudo susto: un «vestiglo» (1008b), «la más grande fantasma» (1008c), un monstruo que ni sacado del Apocalipsis de san Juan, una yegüeriza. Alda por nombre. Le pidió «posada» (1009b) y lo llevó a la Tablada. Alda cra gigantesca en la talla y en los miembros, y horrorosa. «Dixo me la moça: 'Pariente, mi choça. / El que en ella posa / Con migo desposa, / 0 me da soldada'» (1027). Él se excusó de lo primero, diciéndole que era «"cassado / aquí en Ferreros'», y le ascguró que le pagaría a la vuelta, pero ella no le fió, no se fió (1006-1042).

Juan Ruiz nunca pagó sus favores a las montesas, aunque les había prometido mucho, trapitos de colores, cobres y estaños, que se casaría. Como no fuera con coplas burlonas, canciones, un baile... inventando todo un género, el de las cantigas de serrana. El Arcipreste se encontró con la serrana de veras y en broma, en versos y en fantasía. Entonces declara que, harto de aquel «rroído» (1043c), se fue a guardar "vigilia» a «un logar onrrado, / muy santo e muy devoto, / Santa María del Vado" (1044abc). En la misma ermita escribió unas cantigas para la Reina, su Señora (1043-1048).

Todas esas serranas, la Chata, la vaqueriza, Gadea, Menga Llorente o Alda, son contrahechuras de Lilith, mujeres malcasadas o por casar que van detrás del amor. En la Virgen del Vado ves el otro aspecto de Lilith: la Madre a la que le han matado el Hijo, la diosa casta de la montaña.

\section{3. La Serrana de la Vera}

Vistas las que conoció, o soñó que conocía, el Arcipreste, queda la serrana más tremenda, la de Garganta la Olla, en la comarca de la Vera de Plasencia. Aunque viene con retraso (en los romanceros nuevos peninsulares, en la comedia de los siglos de oro), conserva rasgos muy primitivos que le dan estatura mítica, emparentándola con sus hermanas mayores, la Lilith oriental, las lamias, las empusas.

\section{3. 1. Pintas}

La Serrana de la Vera es siempre blanca y rubia, y con esto se señala que los montes no son su sitio natural, sino forzoso. Y lleva traje de cazadora. Cuando Lope de Vega va a sacarla a escena en el tercer acto de su comedia, acota: «Sale Leonarda, como serrana, con capote de dos haldas, y faldón de pellejo de tigre y montera de lo mismo, zapato y polaina, espada en tahalí y arcabuz». Cuatro villanos la cantan después «ojigarza, rubia y branca», y Juan la describe «blanca 


\section{MALAS DOÑAS}

y rubia, zarca y bella. / (...) / El cabello en crespos rizos / debajo de una montera, / un arcabuz en el hombro / y una espada en la correa». En un romance es «...blanca, rubia, ojimorena. / Trae el cabello trenzado / debajo de una montera, / y porque no la estorbara, / muy corta la faldamenta» ${ }^{6}$. En otro «blanca, rubia, ojimorena; trae recogidos los rizos / debajo de la montera; / al uso de cazadora / gasta falda a media pierna, / botín alto y argentado / y en el hombro una ballesta; / de perdices y conejos / lleva la pretina llena»? En otro aún «se pasea la Serrana / bien calada su montera, / con la honda en la cintura, / y terciada su escopeta» ${ }^{8}$.

\section{3. 2. El cuento}

Esta serrana fue troglodita, y hacía y deshacía en una caverna que cerraba con la muela que hoy sirve de pila bautismal en la iglesia del lugar. Arrancaba robles de cuajo. Pueden verse las señales de sus pisadas enormes, y los monumentos megalíticos que levantaba. Era, se ve enseguida, de la raza condenada de los gigantes.

Se perdía uno en sus alrededores y ella te metía en su gruta. Fuera tenía amontonadas las calaveras de todos sus pobres convidados. O había un pequeño cementerio, lleno de cruces. Cebaba a los desviados y, después de la cena, venía, si sc podía, el amor.

-Cierra la puerta -mandaba la serrana, y él, más astuto, la dejaba entreabierta.

El viajero, en unas, cansa a la serrana con la «lucha». En otras, toca él un rabelillo, y ella su vihuela, y el sueño derrota antes a la serrana. Entonces él sale de puntillas, con los zapatos en la mano, y echa a correr. La de la Vera se despierta y lo sigue saltando y brincando «de peña en peña». Primero tira con la honda y le quita la montera, o derriba, fallando, una encina. Cuando ve que se le va, vienen los ruegos:

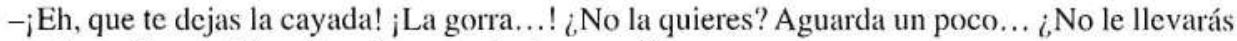
esta carta a mi padre? Le dices "que quedo buena...".

Pero él está sordo a la soledad de la serrana, y, como se ve seguro, contesta muy aliviado: «Enviadla vos con otro, / o ser vos la mensajera»".

El romance tiene una continuación curiosísima: «iAnda -le dice-, villano, / que me dejas descubierta, / que mi padre era pastor / y mi madre fue una yegua, / que mi padre comía pan / y mi madre comía hierba!» ${ }^{10}$.

La Alda que Juan Ruiz se encontró en la Tablada era una «yeguarisa trifuda» (1008d), o sea, robusta, y, quizás por la cercanía del ganado que cuidaba, «era grand yegua cavallar» (1010b). Quiere decir que parecía una yegua. A no ser que recordase vagamente el mito que sí conoció el romance mencionado.

En la acrópolis de Feneo, Odiseo, cuando encontró sus yeguas allí, pagó, agradecido, para que hicieran una estatua de Poseidón Hipio y levantasen una capilla a Ártemis. Es que son, estos divinos, los patrones de los caballos (Pausanias, VIII, 14: 4-5). Pausanias cuenta en dos lugares lo del dios del mar y Deméter:

6.- Esta versión la recogió Gabriel Azedo de la Berrueza en 1667. En Caro Baroja (1989: 271- 272).

7.- Ramón Menéndez. Pidal, Flor nueva de romances viejos, Buenos Aires, 1938, pp. 298-301. En Caro Baroja (1989: 274-276).

8.- Recogida por Julio Ateneo y dada, según su manuscrito, por Bonifacio Gil, Cancionero popular de Extremadura,

II, en Badajoz, en 1956. En Caro Baroja (1989: 276-278).

9.- Esta versión la recogió Gabriel Azedo de la Berrueza en 1667. En Caro Baroja (1989: 271-272).

10.- Recogida por Julio Ateneo y dada, según su manuscrito, por Bonifacio Gil, Cancionero popular de Extremadura,

II, en Badajoz, en 1956. En Caro Baroja (1989: 276-278). 


\section{MANUEL PALAZÓN BLASCO}

Dicen que Deméter, cuando andaba errante en busca de su hija, la siguió Posidón, que deseaba unirse a ella, y ella, transformándose en una yegua, pastaba con las de Oncio, pero Posidón comprendió que había sido engañado y se uní́ con Deméter tomando forma de caballo... Dicen que Deméter tuvo de Posidón una hija, cuyo nombre no acostumbran a decir a los no iniciados, y el caballo Arión. Por esto dicen que fueron los primeros arcadios que llamaron Hipio a Posidón (Pausanias, VIII, 25: 1-10).

El otro monte, el Elaio, está unos treinta estadios más allá de Figalía, y allí hay una cueva consagrada a Deméter de sobrenombre Melena. Lo que dicen los de Telpusa respecto a la unión de Posidón y Deméter, de la misma manera lo creen los de Figalía, pero éstos dicen que Deméter dio a luz no un caballo, sino a la que los arcadios llaman Despena. Dicen que, después de esto, encolerizada contra Posidón y afligida por el rapto de Perséfone, se puso un vestido negro, fue a esta cueva y estuvo allí durante mucho tiempo... Las cosechas, como no las gobernaba ella, se perdían, y la hambruna diezmaba a los hombres. Zeus le envió a las Moiras, y Deméter depuso su cólera y cedió en su pena. Dicen los figaleos que por esto consideran consagrada la cueva a Deméter y en ella ofrendaron una imagen de madera. Hicieron la imagen de la siguiente manera. Estaba sentada sobre una roca y tenía el aspecto de una mujer, excepto la cabeza. Tenía la cabeza y la cabellera de caballo, con figuras de serpientes y otros animales que crecían de su cabeza. Vestía hasta los pies. Tenía un delfín en la mano y una paloma en la otra...Dicen que la llaman Melena porque la diosa tenía vestido negro (Pausanias, VIII, 42).

La Serrana de la Vera, en el final de ese romance, tiene algo, ¿no?, de la misteriosa (sólo los iniciados averiguan su nombre) hija de la Virgen Silvestre, o de esta otra Diana encovada, enlutada, rabiosa, asqueada del cachondo Posidón, que la montó a la fuerza, y que representan, recordando su mala hora, con cabeza caballuna y tocada con mitra de scrpientes (;igual que la Lilith de las tablillas sumerias!). Diana es la «reina de las selvas» (Séneca, Hipólito, 406), «dueña de los montes» (Catulo: Carmen ad Dianam, 34, 9), «señora de las ficras» (Ilíada, XXI, 470) $)^{11}$, cazadora y, sobre todo, virgen helada, muy enemiga de los hombres. Lo mismo que las otras criaturas que estamos estudiando.

\section{3. 3. Ñublos}

Julio Caro Baroja se ocupó de la Serrana de Garganta la Olla en varios trabajos, y dio en el clavo al pasar lista a su parentela. Es él quien, al encontrar el raro romance que termina haciendo a la serrana hija de una yegua, apunta a Diana. Dice también: «...se cree que llevó grandes masas de piedra de un sitio a otro y que dejó huellas de sus pies sobre determinadas rocas y peñascos. Recordaba, en fin, algunos de los rasgos que los campesinos vascos dan a 'Mari' o la 'Dama'» (Caro Baroja, 1989: 281). Y añade (1989: 280): «....ahora estoy más inclinado todavía a creer que la 'Serrana' es... un numen folklórico de las alturas, de las cuevas... (...) se le siguen atribuyendo ciertos rasgos físicos ciclópeos, como si fuera una especic de Polifemo hembra». Cita, además, a San Martín Dumiense ${ }^{12}$, que explicaba así la presencia de estos seres femeninos, igualándolos: «en los ríos, las lamias; en las fuentes, las ninfas; en las selvas, las dianas: todas demonios o espíritus malignos, localizados después de su expulsión del cielo».

Es normal, entonces, que en la comedia de Vélez de Guevara avisen a Leonarda, la serrana: «...y el cura / como ñublo te conjura / a la puerta de la ygrexa...»" ${ }^{13}$. El nublo es indicio de tormenta, pero también, según trae el Diccionario de Autoridades, «vale la especie que amenaza algún riesgo o turbación en el ánimo». La serrana, en fin, imaginada en sus cavernas, en los oteros, en los estrechos pasos de las cordilleras, inventada, soñada, temida, descada, es ese ñublo que nos desgracia, o sea, nos pierde para Dios / para el Cielo.

11.- Caro Baroja (1989: 293, notas 110 y 111).

12.- San Martín Dumiense, "De correctione rusticorum", 3. En España Sagrada, XV, Madrid, 1906, p. 427. En Caro Baroja (1989: 292).

13.- Caro Baroja (1989: 290-291). 


\section{MALAS DOÑAS}

\section{Epílogo}

Lilith, Lamia, las empusas, las serranas, las vírgenes morenas de las cuevas... son aspectos de la misma brava señora que tuvo que echarse al monte para que no la sopearan. A servir se quedaron las mansas cvas. "Doñas", las he llamado, pues, antes de su desgracia, tuvieron todas título y fueron muy honradas. "Malas" les dicen ellos, porque se les malearon. Los universos fantásticos tienen sus propias geografías. Éste tiene la suya, dura, desabrigada, la de la nada del Prólogo, la del vacío último. Y en él se apañan, lo mejor que saben, estas antiguas divinas. Ninguna tiene padre, ni Padre. DesPadradas, sólo ellas no son hijas, y tienen, por ello, libertad para gozar. Por eso dan miedo.

\section{BIBLIOGRAFÍA}

\section{Sobre Lilith:}

ANÓNIMO (1938): "Gilgamesh and the Huluppu-Tree: A Reconstructed Sumerian Text", Assyriological Studies of the Oriental Institute of the University of Chicago, Chicago.

(1988): Poema de Gilgamesh. Traducido y anotado por Federico Lara Peinado, Madrid, Tecnos.

(1992): La reina de Saba. Según el texto y la traducción de J. C. Mardrus, en versión de Esteve Serra, Palma de Mallorca, Lunas.

KRAMER, Samuel Noah (1972): Summerian Mythology: A Study of Spiritual and Literary Achievement in the Third Millennium B. C. Pennsylvania University Press.

\section{Sobre las Serranas:}

ELIA, Paola, ed. (2002): El "Pequeño Cancionero" (Ms. 3788 BNM). La Coruña, Toxosoutos.

LAPESA, Rafael (1979): "Las serranillas del Marqués de Santillana", en La obra literaria del Marqués de Santillana. Ínsula, Madrid, 1957, pp. 52-59, 61-63. En Deyermond (1979), 320325 .

MENÉNDEZ PELAYO, Marcelino (1949): Estudios sobre el teatro de Lope de Vega. Ed. Enrique Sánchez Reyes, Santander, Aldus S. A. de Artes Gráficas.

MENÉNDEZ PIDAL, Ramón (1957): "La primitiva poesía lírica española”. En Menéndez Pidal (1957), 197-269.

PAUSANIAS (1995): Descripción de Grecia, Libros VIII-X. Trad. y notas de María Cruz. Herrero Ingelmo, Barcelona, Planeta-De Agostini.

RUIZ, Juan, Arcipreste de Hita (1990): El Libro de Buen Amor. Ed. G. B. Gybbon-Monypenny, Madrid, Castalia.

TORRECILLA DEL OLMO, Francisco, ed. (1997): Canciones populares de la tradición medieval. Madrid, Akal.

VEGA, Lope de (1991), La Serrana de la Vera. Ed. de Federico Carlos Sáinz de Robles, en Obras Selectas, Tomo III, México D. F., Aguilar.

\section{Obras básicas de referencia:}

BIBLIA DE JERUSALÉN (1975): Biblia de Jerusalén. Ed. española dirigida por José Ángel Ubieta, Bilbao, Desclée de Brouwer.

CARO BAROJA, Julio (1989): Ritos y mitos equívocos. Madrid, Istmo, Col. Fundamentos 100. (1991): De los arquetipos y leyendas. Madrid, Istmo, Col. Fundamentos 113. 


\section{MANUEL PALAZÓN BLASCO}

COVARRUBIAS OROZCO, Sebastián de (1995): Tesoro de la lengua castellana, o española. Edición de Felipe C. R. Maldonado, revisada por Manuel Camarero, Madrid, Castalia, Nueva Biblioteca de Erudición Crítica.

DEYERMOND, Alan, dir. (1979): Historia y Crítica de la Literatura Española: vol. 1., Edad Media, Barcelona, Crítica.

ENCYCLOPEDIA BRITANNICA (1989): Encyclopedia Britannica.

GRAVES, Robert (1991): Los mitos griegos. Madrid, Alianza.

_ - y PATHAI, Raphacl (2000): Los mitos hebreos. Trad. Javier Sánchez. García-Gutiérrez, Madrid, Alianza, "Religión y Mitología".

MENÉNDEZ PIDAL, Ramón (1957): Estudios Literarios. Madrid, Espasa-Calpe.

MOLINER, María (1986): Diccionario de uso del español. Madrid, Gredos.

OXFORD ENGLISH DICTIONARY (1999): Oxford English Dictionary (CD-ROM). Oxford, Oxford U. Press, $2^{\text {a }}$ ed.

REAL ACADEMIA ESPAÑOLA (1990): Diccionario de Autoridades (AUT). Madrid, Gredos, ed. facsímil.

— (1992): Diccionario de la lengua. Madrid, Espasa Calpe, $21^{\mathrm{a}}$ ed. 